\title{
Robot-assisted endoscopic airway reconstruction in rabbits, with the aim to perform robot-assisted thoracoscopic bronchoplasty in human subjects
}

Ryuichi Waseda, MD, ${ }^{a}$ Norihiko Ishikawa, MD, $\mathrm{PhD}^{\mathrm{b}}$ Makoto Oda, MD, $\mathrm{PhD},{ }^{\text {a }}$ Isao Matsumoto, MD, PhD, ${ }^{\text {a }}$ Yasuhiko Ohta, MD, PhD, ${ }^{\text {a }}$ Noriyuki Inaki, MD, PhD, ${ }^{\text {b }}$ Yasumitsu Hirano, MD, PhD, and Go Watanabe, MD, PhD ${ }^{\text {a }}$

From the Departments of General and Cardiothoracic Surgery and Telesurgery and Geomedicine, ${ }^{\text {b }}$ Kanazawa University School of Medicine, Kanazawa, Japan.

Received for publication April 17, 2007; revisions received June 2, 2007; accepted for publication July 5, 2007.

Address for reprints: Ryuichi Waseda, MD, Department of General and Cardiothoracic Surgery, Kanazawa University School of Medicine, 13-1 Takaramachi, Kanazawa 920-8641, Japan. (E-mail: wryuichi@hotmail.com)

J Thorac Cardiovasc Surg 2007;134:989-95

$0022-5223 / \$ 32.00$

Copyright @ 2007 by The American Association for Thoracic Surgery

doi:10.1016/j.jtcvs.2007.07.002
Objective: Robotic telemanipulation systems have been introduced recently to enhance the surgeon's dexterity and visualization in endoscopic surgery and thus facilitate refined dissection, suturing, and knot tying. This study examined the technical feasibility of performing safe and efficient robot-assisted, hand-sewn endoscopic airway reconstruction in a rabbit model.

Methods: A total of 18 tracheal anastomoses were performed in rabbits, with 6 anastomoses performed endoscopically using the da Vinci Surgical system (Robot group), 6 anastomoses performed using traditional thoracoscopic surgical instruments (VATS group), and 6 anastomoses performed using open surgical instruments (Open group). Anastomosis time and complications were recorded. The effectiveness of anastomoses was evaluated by postoperative observation of all rabbits for 8 weeks and measurement of anastomotic stricture and pathologic findings. These parameters and anastomosis time were compared between groups.

Results: In all cases in the Robot group, the procedure was completed endoscopically. No perioperative or postoperative complications were encountered. Mean procedure time of the Robot group was $14.1 \pm 2.6$ minutes (mean \pm standard deviation). Anastomosis time in the Robot group was significantly shorter than in the VATS group (33.5 \pm 5.2 minutes, $P=.0039)$ and was not significantly different in the Open group (11.4 \pm 2.3 minutes, $P=.1282)$. All anastomoses in the Robot group remained mechanically intact, and all parameters were comparable with those of the open surgery group.

Conclusions: The technical feasibility of performing safe and efficient robot-assisted endoscopic airway reconstruction was repeatedly demonstrated in a rabbit model. Robotic assistance significantly improved the time associated with and the quality of endoscopic airway reconstruction.

1 lthough widely accepted because of its merits, endoscopic surgery is known to have limitations regarding the dexterity and depth perception of the surgeon. Working through trocars limits the degree of freedom of movement and introduces an inverted instrument response and variability in excursion of the instrument tip directly related to the part of the instrument that is brought into the body cavity. These disadvantages require surgeons to acquire new techniques and practices in performing complex surgical maneuvers during endoscopic procedures, such as challenging dissection and suturing. ${ }^{1-9}$

Telemanipulation systems have recently been introduced, with the objective of enhancing the surgeon's view and dexterity during endoscopic surgery. These systems alleviate most of the previously mentioned disadvantages and should be able to support surgeons in a precise and efficient manner. This might expand the list of indications for routine endoscopic surgery and bring about high-end 


\section{Abbreviations and Acronyms \\ VATS $=$ video-assisted thoracic surgery}

procedures, such as cardiac surgery, vascular reconstruction, pancreatic surgery, and completely laparoscopic intestinal resections. ${ }^{10-20}$

In the field of general thoracic surgery, although recent robot-enhanced video-assisted thoracic surgery (VATS) anatomic pulmonary lobectomy and VATS mediastinal tumor resections ${ }^{21-24}$ were reported, whether this technology has any benefits remains unclear. Although surgeons working with these systems express enthusiasm for the gains in control and visualization, the immediate advantages of robotic systems in general thoracic surgery are less apparent compared with those in cardiac surgery. Statistical proof of the merits will thus be hard to obtain in the short term within the spectrum of well-documented routine thoracoscopic interventions. This study using the da Vinci Surgical System (Intuitive Surgical, Sunnyvale, Calif) investigated the efficacy of robotic suturing and knot tying, with the aim of testing the applicability of robot-enhanced endoscopic airway reconstruction.

\section{Materials and Methods}

\section{Airway Reconstruction Model in Rabbits}

Subjects comprised 18 Japanese white female rabbits with a median weight of $2.8 \mathrm{~kg}$ (range, $2.5-3.0 \mathrm{~kg}$ ). All experimental procedures were performed in accordance with the "Principles of laboratory animal care" formulated by the National Society for Medical Research and the "Guide for the care and use of laboratory animals" prepared by the Institute of Laboratory Animal Resources of the National Research Council (National Academy Press, revised 1996). Anesthesia was induced with intramuscular injection of $10 \mathrm{mg} / \mathrm{kg}$ ketamine and maintained with $3 \mathrm{mg} / \mathrm{kg}$ intravenous sodium pentobarbital and $1 \%$ lidocaine as local anesthesia. Rabbits underwent surgical intervention in a horizontal supine position. The trachea was exposed, and 4 rings were resected with the open technique. In this study prepared tracheas were used as models of the human bronchus. End-to-end tracheal anastomoses were performed in 3 different ways, with 6 rabbits undergoing operations with the da Vinci Surgical System (Robot group), 6 rabbits undergoing operations with traditional thoracoscopic surgical instruments (VATS group), and the remaining 6 rabbits undergoing operations with conventional open surgical instruments (Open group). All procedures were performed by the same experienced endoscopic surgeon. Before operations with the animal models, the surgeon trained by performing 10 end-to-end anastomoses with 6-mm polytetrafluoroethylene prostheses (WL Gore \& Associates, Flagstaff, Ariz) for each procedure. All rabbits were observed for 8 weeks postoperatively and then killed for evaluation of anastomosis.

\section{Robot-assisted Surgical Procedures}

The da Vinci Surgical system was used in the Robot group. The main technologic advantages of this system are a true 3-dimensional endoscope providing a high-resolution binocular view of the surgical field, an Endowrist instrument system (Intuitive Surgical) capable of 7 degrees of freedom and 2 degrees of axial rotation to replicate human wrist-like movements and tremor filtration, and motion-scaling systems to enhance surgical dexterity.

Rabbits were operated on in a surgical training box (Tuebinger MIC-Trainer; Richard Wolf GmbH, Knittlingen, Germany). A $12-\mathrm{mm}$ trocar for the $30^{\circ}$-down camera was placed above the trachea. Two 8-mm trocars for the robotic arms were placed symmetrically to the right and left (Figure 1). Endowrist Black Diamond arms (Intuitive Surgical) were chosen for both arms. For this procedure, the robot was positioned at the right side of the animal. End-to-end anastomoses were performed in a running fashion with a 12-cm double-armed 5-0 BIOSYN suture (Tyco Health Care, Norwalk, Conn). The running suture was prepared by tying together the ends of two 6-cm sutures of 5-0 BIOSYN (Figure 2). The first running suture was started posteriorly (Figures $3, A$, and $4, A$ ) and directed to the membranous wall of the trachea anteriorly (Figures $3, B$, and $4, B$ ), and then a second suture was directed to the cartilage wall anteriorly (Figures 3, $C$, and 4, C). After the anastomosis was completed, both sutures were tied at the top of the tracheal cartilages (Figures $3, D$, and $4, D$ ). The motionscaling system of the system was set to 5:1 (ultrafine mode) in this procedure.

\section{Traditional Thoracoscopic Surgical Procedure}

In the VATS group, rabbits were operated on in the same setting as used for the Robot group. A standard endoscopic needle holder and forceps and a $30^{\circ}$-down 2-dimensional camera (Karl Storz, Tuttlingen, Germany) were used. The 2-dimensional camera was fixed in a passive camera holder, according to the preferences of the surgeon. The training box was set on a table of adjustable height. In this group an identical procedure was performed by using the same materials and the same methods as used for the Robot group.

\section{Open Surgical Procedure: Control Group}

The Open group formed the control group. Rabbits underwent operations in the same horizontal supine position. Anastomoses were performed in a standard running fashion with normal doubleended 5-0 BYOSYN sutures.

\section{Data Collection and Measurements}

Conversions and intraoperative complications were recorded in all groups. Time to anastomosis and number of stitches for anastomosis were documented in all cases. Anastomosis time was measured from the time suturing began until tying was finished. In addition, the number of times the stitch was broken during suturing was registered. The postoperative course for 8 weeks was evaluated, focusing on complications. At autopsy, the trachea, including the anastomosis, was resected, and the tissue around the anastomosis was explored, specifically searching for signs of anastomotic failure. Before tracheal resection, bronchoscopy with a 5-mm telescope was performed to endoscopically evaluate the anastomosis in all cases. 


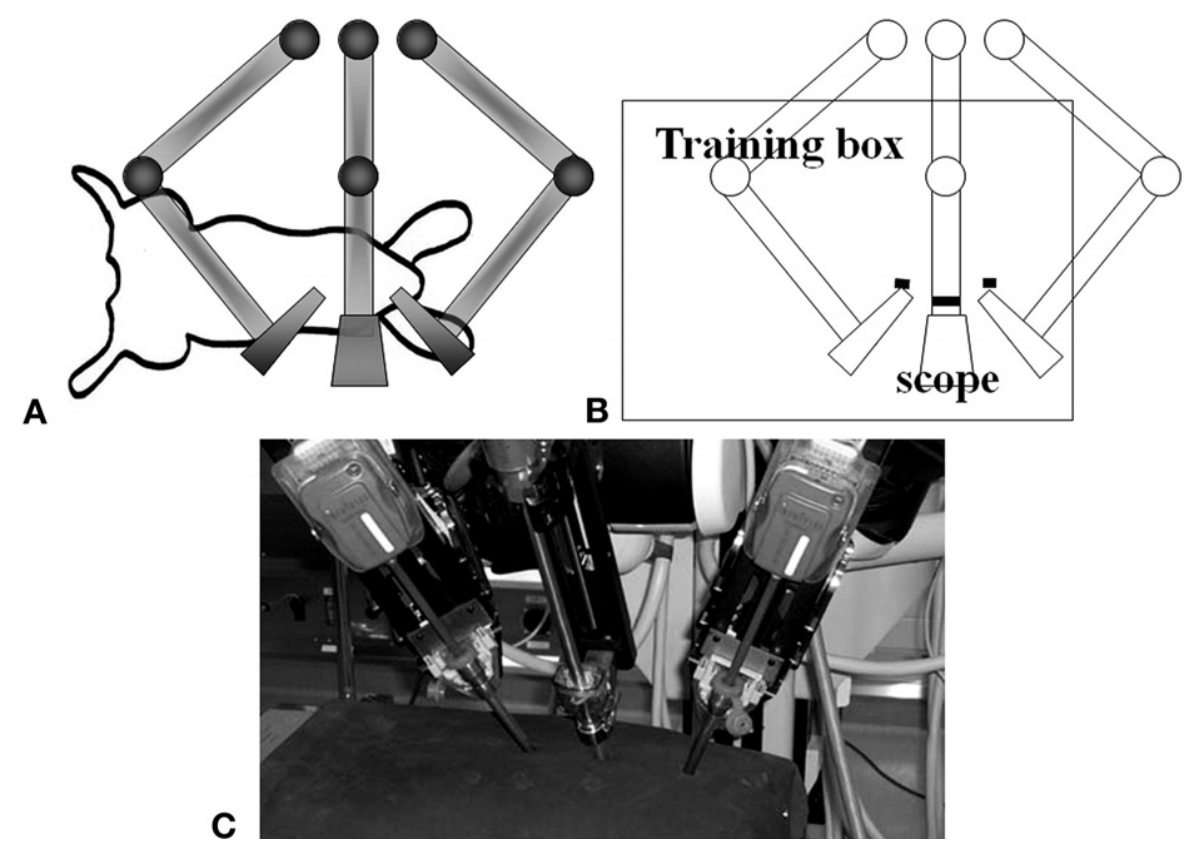

Figure 1. Position of the da Vinci Surgical System. A, Schema; B, schema with training box; C, photograph.

The effectiveness of anastomoses was evaluated according to postoperative complications and measurements of anastomotic stricture in endoscopic and pathologic findings. Sections were cut from tissue blocks onto coated glass slides and stained with hematoxylin and eosin. The anastomotic stricture was quantitatively analyzed in pathologic specimens on a Windows personal computer with Scion Image software (Scion Corp, Frederick, Md). Stricture was defined as the area inside the cartilaginous ring after subtracting the area of the patent lumen. The anastomotic stricture rate was expressed as the percentage stricture of the anastomotic site relative to the normal site $1 \mathrm{~cm}$ proximal to the anastomosis.

\section{Statistical Analysis}

All data were expressed as the mean \pm standard deviation. Comparative analysis was performed with a Mann-Whitney $U$ test by using StatView software (SAS Institute, Cary, NC).

\section{Results}

Intraoperative results are shown in Table 1. No groups displayed any intraoperative conversions or complications, and all procedures in the Robot and VATS groups were

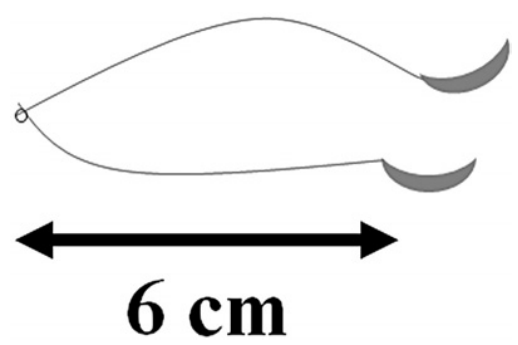

Figure 2. Schema of the $12-\mathrm{cm}$ double-armed suture. completed endoscopically. In all cases 5-0 BIOSYN sutures were not torn during suturing of the anastomosis. Mean anastomosis time was $14.1 \pm 2.6$ minutes in the Robot group compared with $33.5 \pm 5.2$ minutes in the VATS group and $11.4 \pm 2.3$ minutes in the Open group. Anastomosis time in the Robot group was significantly shorter than in the VATS group $(P=.0039)$ and was not significantly different in the Open group $(P=.1218)$. The number of stitches tended to be less in the VATS group than of those in the other 2 groups $(P=.0547)$.
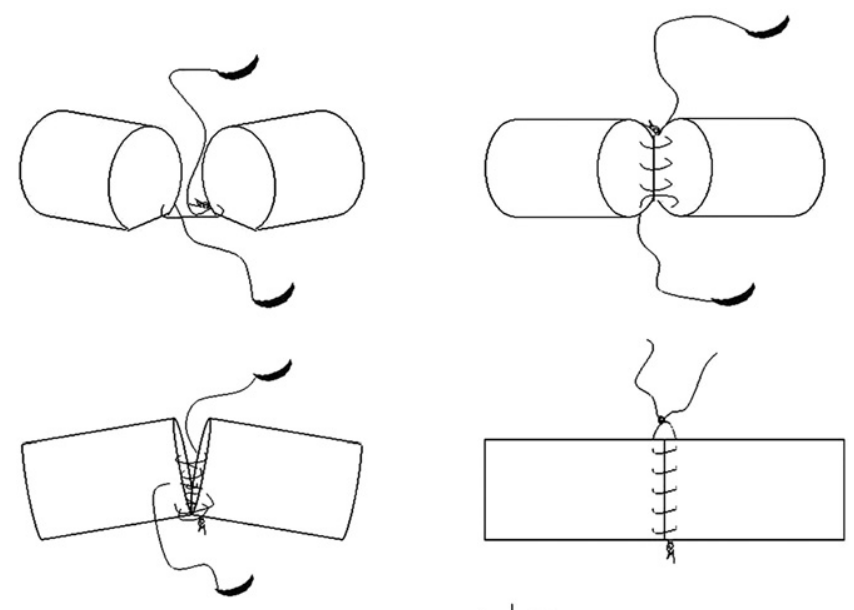

\begin{tabular}{l|l} 
A & B \\
\hline C & D
\end{tabular}

Figure 3. Schema of anastomosis. 

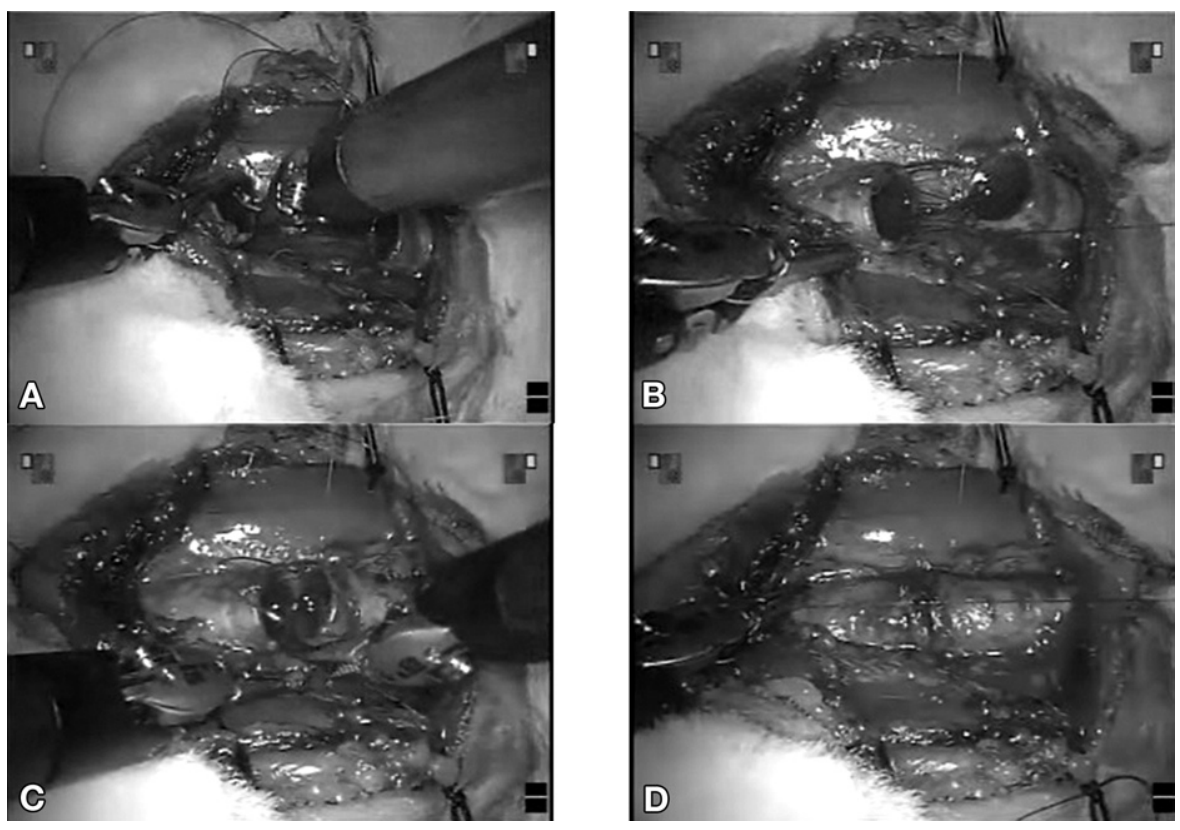

Figure 4. Robot-assisted airway reconstruction.

Postoperative results are shown in Table 2. All rabbits survived for 8 weeks postoperatively without complications. At autopsy, no signs of leakage from the anastomosis were found in any groups. With regard to anastomotic stricture, bronchoscopic and pathologic findings were comparable between the Robot and Open groups. In bronchoscopic findings anastomotic stricture was defined as cases in which a 5-mm telescope could not pass the anastomotic site. Anastomotic stricture was apparent both bronchoscopically and pathologically in 2 cases in the VATS group (Figures 5 and 6). Furthermore, the anastomotic stricture rate was significantly higher in the VATS group than in the Robot group $(P=.0065)$.

\section{Discussion}

Robotic systems for endoscopic surgery were introduced in the late 1990s to enhance maneuverability, visualization, and ergonomics for minimally invasive thoracoscopic and laparoscopic surgery. ${ }^{10-20}$ Endoscopic beating-heart surgery was the initial field of interest because the technical challenge of this procedure surpassed the reach of traditional endoscopic techniques. ${ }^{10,12,13,15,16,18}$ Interest in this area has recently expanded to general thoracic surgery, such as VATS anatomic pulmonary resections and VATS mediastinal tumor resections. ${ }^{21-24}$ However, in the field of general thoracic surgery, whether this robotic technology offers any benefits remains unclear. Statistical proof of the merits of this approach will be hard to obtain from routine thoracoscopic interventions. At this point, the subjectively apparent advantages of robotic surgical systems will therefore have to be proved by facilitating or supporting advanced thoracoscopic interventions, such as procedures requiring suturing and knot tying. Robot-assisted laparoscopic suturing has recently been introduced in various procedures, including intestinal anastomosis, and feasibility has been demonstrated from promising initial experiences. ${ }^{16,19}$ However, no reports have described robot-assisted endoscopic manual airway reconstruction in live animals and human subjects.

Table 1. Intraoperative data

\begin{tabular}{|c|c|c|c|c|c|}
\hline & \multicolumn{5}{|c|}{$P$ value } \\
\hline & Robot group & VATS group & Open group & $\begin{array}{l}\text { Robot group vs } \\
\text { VATS group }\end{array}$ & $\begin{array}{l}\text { Robot group vs } \\
\text { Open group }\end{array}$ \\
\hline Conversions & 0 & 0 & 0 & & \\
\hline Complications (intraoperative) & 0 & 0 & 0 & & \\
\hline Time (min) & $14.1 \pm 2.6$ & $33.5 \pm 5.2$ & $11.4 \pm 2.3$ & $.0039 *$ & .1218 \\
\hline Stitches & $12.0 \pm 1.3$ & $10.5 \pm 0.8$ & $12.0 \pm 1.3$ & .0547 & .9999 \\
\hline Suture tears & 0 & 0 & 0 & & \\
\hline
\end{tabular}

*Statistically significant. VATS, Video-assisted thoracic surgery. 
Table 2. Postoperative data

\begin{tabular}{lcccc}
\hline & \multicolumn{3}{c}{$\boldsymbol{P}$ value } \\
\cline { 2 - 5 } & Robot group & VATS group & Open group & $\begin{array}{c}\text { Robot group vs } \\
\text { VATS group }\end{array}$ \\
\hline Complications (postoperative) & 0 & 0 & 0 & \multicolumn{1}{c}{$\begin{array}{c}\text { Robot group vs } \\
\text { Open group }\end{array}$} \\
Stricture (bronchoscopy) & 0 & 2 & 0 & $.0065^{*}$ \\
Stricture rate (\%) & $8.3 \pm 1.6$ & $12.9 \pm 2.8$ & $8.4 \pm 1.6$ & .9362 \\
\hline
\end{tabular}

*Statistically significant. VATS, Video-assisted thoracic surgery.

Some studies have examined the maneuvers and confirmed safety for endoscopic intestinal anastomoses and vascular anastomoses, but few have investigated maneuvers and safety in endoscopic bronchial and tracheal anastomoses. Actually, relatively few cases require airway reconstruction, such as bronchial and tracheal anastomoses. Common procedures requiring airway reconstruction are sleeve lobectomy and segmentectomy for lung cancer and partial resection of the bronchus and trachea for benign and lowgrade malignant tumors of the bronchus and trachea. In any case, these procedures aim for preservation of respiratory function, and therefore a minimally invasive operation is well indicated in such procedures. However, endoscopic airway reconstruction is not generally performed. Some reasons are thus considered.

First, there are not any good stapling devices, and techniques for bronchial and tracheal anastomosis differ from those for intestinal anastomosis.
Second, anatomic features of the bronchus and trachea differ substantially from the intestine and blood vessels, namely with the presence of cartilaginous parts. Grasping and turning over tissue of the anastomotic site is thus difficult, representing a serious matter when performing accurate anastomosis in conventional endoscopic surgery, where the visual field and manipulation are restricted.

Third, failure of bronchial and tracheal anastomoses results in fatal damage, and recovery from such an event is very difficult. On the other hand, airway reconstructions in the thoracic cavity are difficult, even in open surgical intervention, because of the poor visual field and ribs. Endoscopic surgery might offer a potential solution to these issues. To solve the problems of conventional endoscopic and open operations, we chose to use the da Vinci Surgical system, which is good for working in deep, small surgical spaces. This study established a procedure for robot-assisted airway reconstruction and evaluated feasibility and safety.
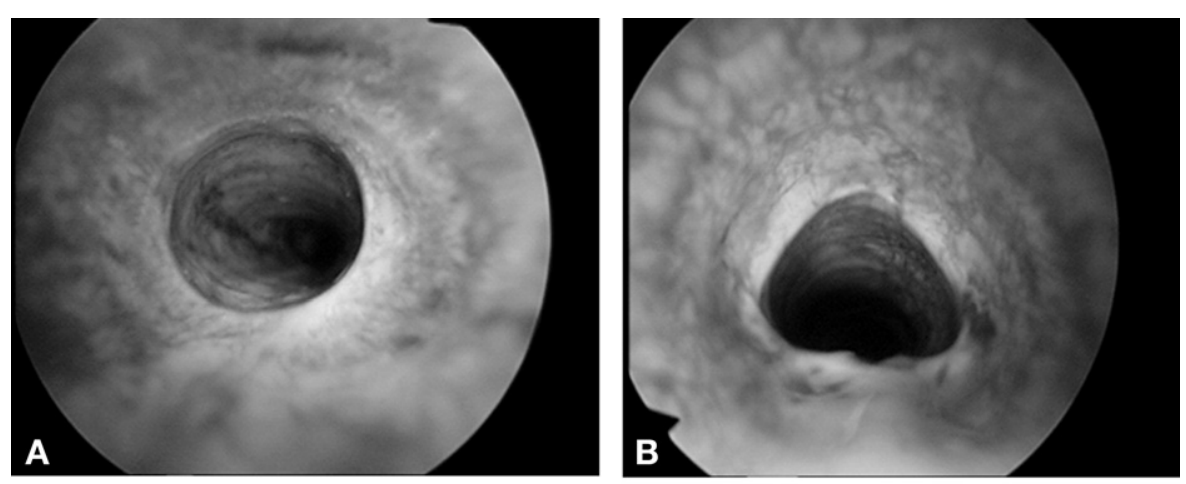

Figure 5. Bronchoscopic findings. A, Robot group; B, Open group; C and D, VATS group ( 2 cases with obvious anastomotic stricture). VATS, Videoassisted thoracic surgery.
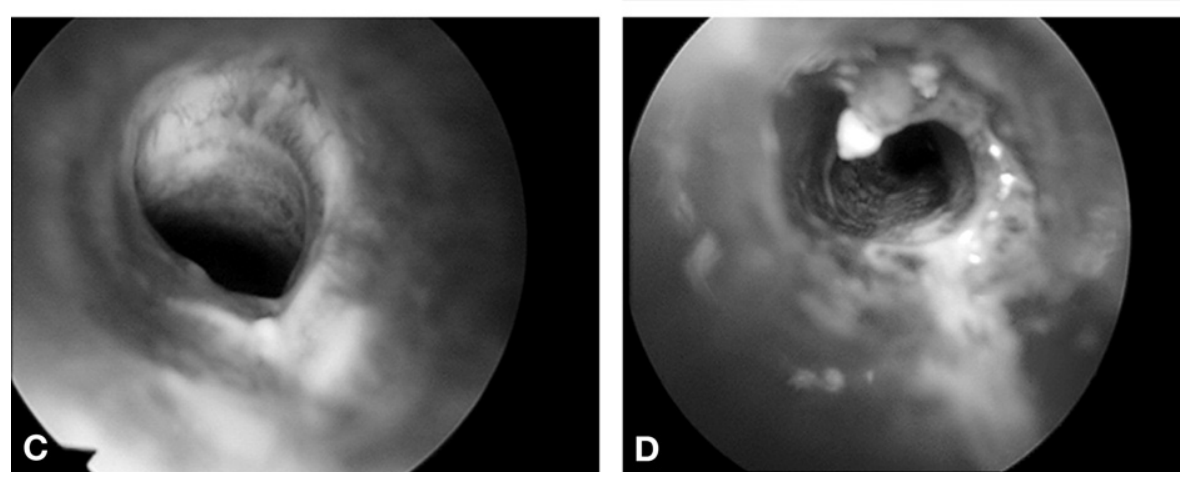

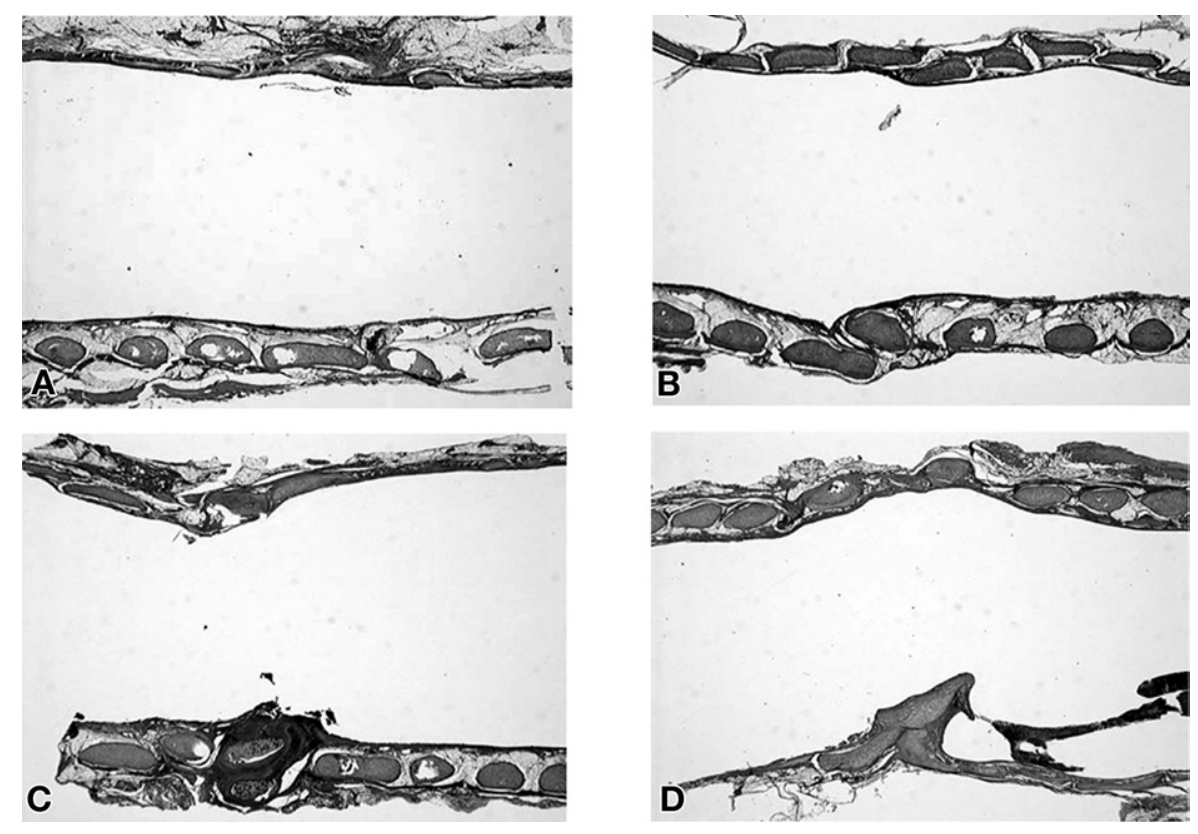

Figure 6. Pathologic findings. (Hematoxylin and eosin stain, original magnification $40 \times$.) A, Robot group; B, Open group; C and D, VATS group (2 cases with obvious anastomotic stricture). VATS, Video-assisted thoracic surgery.

Rabbit trachea was used as the model of human bronchial end-to-end anastomosis, and 5-0 BIOSYN sutures were used in single-layer running fashion as the anastomotic procedure. Kutlu and Goldstraw ${ }^{25}$ reported that bronchial and tracheal anastomoses in running fashion are quick and technically easier to perform than in interrupted fashion and are sufficiently safe. The aim of this study was to evaluate the usefulness of robot-assisted procedures in comparison with traditional thoracoscopic and open procedures.

Our intraoperative data showed that anastomosis time in the Robot group was significantly shorter than in the VATS group and was almost equal to that in the Open group. In the Robot and Open groups ideal procedures were performed with 12-stitch anastomoses in this model. However, in the VATS group we supposed that anastomoses were not performed sufficiently because a lack and irregularity of stitches led to anastomotic leakage and stricture. Although the lack of tactile response in robotic surgery is well known, no obvious tears in sutures and tissues at the anastomotic site were encountered in this study. The results showing that the robot-assisted procedure was comparable with the open procedure and better than the traditional thoracoscopic procedure are attributable to several factors. First, the end-toend anastomotic procedure in this small tracheal model, even with a running method, was very difficult and required accuracy. In the Robot group, high-resolution 3-dimensional imaging offered an excellent surgical field and allowed efficient and accurate handling of the needle and suture, even in areas that were difficult for the traditional thoracoscopic surgical instruments using Endowrist instruments. Furthermore, handling with the nondominant arm was almost equal to that with the dominant arm in the Robot group, and this ability was very helpful in complex maneuvers. Our results also showed that a lack of tactility might be overcome thanks to superior visualization, suitable instruments, and techniques to avoid directly grasping fragile tissues and sutures.

During the postoperative observation, no complications were seen in any group. However, anastomosis quality differed between each group. Anastomotic stricture is often used in experiments evaluating anastomotic healing and the technical correctness of the anastomosis. In both bronchoscopic and pathologic findings of the anastomotic site, the Robot group was superior to the VATS group and was comparable with the Open group. Furthermore, the anastomotic stricture rate was lower in the Robot group than in the VATS group. These results showed that the quality of anastomoses in the Robot group was equal to that in the Open group and was superior to that in the VATS group. The absence of signs of anastomotic leakage at autopsy supported the feasibility of performing safe tracheal anastomosis in rabbits. The technical quality of endoscopic anastomosis was further demonstrated by comparisons between the Robot, VATS, and Open groups. In the Robot group the finding of adequate passage through the anastomosis without strictures in any cases and a constant distance between stitches further supported feasibility and efficacy.

Intraoperative and postoperative data showed that robotassisted endoscopic airway reconstruction offered highquality results within a reasonable anastomosis time. The open procedure was performed in a very easy situation in 
this study, but the actual surgical field might be deep, small, and with poor vision. In the actual operation, robot-assisted endoscopic airway reconstruction, such as bronchial anastomosis, might be superior to the open procedure. Although there are not so many cases that robot-assisted endoscopic airway reconstruction is needed, we believe this procedure will be indicated clinically. In our institution, Ishikawa and colleagues ${ }^{26}$ reported thoracoscopic robot-assisted bronchoplasty in cadavers, and proper positions of the robotic system and trocars were described. We have recently aimed to perform robot-assisted thoracoscopic bronchoplasty clinically on the basis of this study.

In conclusion, this study demonstrated the feasibility of hand-sewn endoscopic bronchial anastomosis with a robotic system. Under circumstances in which endoscopic surgery becomes very challenging with traditional 4-degrees-offreedom instruments, this new equipment is expected to be of significant support. Continuing research will therefore focus on confirming advantages in technically challenging procedures.

We thank Y. Tanaka, M. Naya, and S. Soga for providing technical support.

\section{References}

1. Kirby TJ, Rice TW. Thoracoscopic lobectomy. Ann Thorac Surg. 1993;56:784-6.

2. Walker WS, Carnochan FM, Pugh GC. Thoracoscopic pulmonary lobectomy. J Thorac Cardiovasc Surg. 1993;106:1111-7.

3. Mckenna RJ. Lobectomy by video-assisted thoracic surgery with mediastinal node sampling for lung cancer. J Thorac Cardiovasc Surg. 1994;107:879-82.

4. Mckenna RJ, Wolf RK, Brenner M, Fischel RJ, Wurnig P. Is lobectomy by video-assisted thoracic surgery an adequate cancer operation? Ann Thorac Surg. 1998;66:1903-8.

5. Bernstein MA, Dawson JW, Reissman P, Weiss EG, Nogueras JJ, Wexner SD. Is complete laparoscopic colectomy superior to laparoscopic assisted colectomy? Am Surg. 1996;62:507-11.

6. Bessler M, Whelan RL, Halverson A, Allendorf JD, Nowygrod R, Treat MR. Controlled trial of laparoscopic-assisted vs open colon resection in a porcine model. Surg Endosc. 1996;10:732-5.

7. Fritsch S, Fourquier P, Gossot D, Colomer S, Celerier M, Revillon Y. Laparoscopic manual intestinal anastomosis: experimental study in a pig model. Ann Chir. 1998;52:574-7.

8. Kockerling F, Rose J, Schneider C, Scheidbach H, Scheuerlein H, Reymond MA, et al. Laparoscopic colorectal anastomosis: risk of postoperative leakage. Results of a multicenter study. Laparoscopic Colorectal Surgery Study Group (LCSSG). Surg Endosc. 1999:13: $639-44$.
9. Watanabe G, Takahashi M, Misaki T, Kotoh K, Doi Y. Beating-heart endoscopic coronary artery surgery. Lancet. 1999;354:2131-2.

10. Mohr FW, Falk V, Diegeler A, Autschback R. Computer-enhanced coronary artery bypass surgery. J Thorac Cardiovasc Surg. 1999;117: $1212-4$.

11. Garcia-Ruiz A, Gagner M, Miller JH, Steiner CP, Hahn JF. Manual vs robotically assisted laparoscopic surgery in the performance of basic manipulation and suturing tasks. Arch Surg. 1998;133:957-61.

12. Boehm DH, Reichenspurner H, Gulbins H, Detter C, Meiser B, Brenner $\mathrm{P}$, et al. Early experience with robotic technology for coronary artery surgery. Ann Thorac Surg. 1999;68:1542-6.

13. Boyd WD, Desai ND, Kiaii B, Rayman R, Menkis AH, Mckenzie FN, et al. A comparison of robot-assisted versus manually constructed endoscopic coronary anastomosis. Ann Thorac Surg. 2000;70:839-42.

14. Cadiere GB, Himpens J, Germay O, Izizaw R, Degueldre M, Vandromme J, et al. Feasibility of robotic laparoscopic surgery: 146 cases. World J Surg. 2001;25:1467-77.

15. Mohr FW, Falk V, Diegeler A, Walther T, Gummert JF, Bucerius J, et al. Computer-enhanced "robotic" cardiac surgery: experience in 148 patients. J Thorac Cardiovasc Surg. 2001;121:842-53.

16. Melfi FM, Mencoci GF, Mariani AM, Angeletti CA. Early experience with robotic technology for thoracoscopic surgery. Eur J Cardiothorac Surg. 2002;21:864-8.

17. Ruurda JP, Broaders IAMJ. Robot-assisted laparoscopic intestinal anastomosis. An experimental study in pigs. Surg Endosc. 2003;17: $236-41$.

18. Morgan JA, Ginsburg ME, Sonett JR, Morales DL, Kohmoto T, Gorenstein LA, et al. Advanced thoracoscopic procedures are facilitated by computer-aided robotic technology. Eur J Cardiothorac Surg. 2003;23:883-7.

19. Ruurda JP, Broeders IAMJ, Pulles B, Kappelhof FM, van der Werken C. Manual robot assisted endoscopic suturing. Surg Endosc. 2004;18: 1249-52.

20. Ruurda JP, Wisselink W, Cuesta MA, Verhagen HJM, Broeders IAMJ. Robot-assisted versus standard videoscopic aortic replacement. A comparative study in pigs. Eur J Cardiothorac Surg. 2004;27:501-6.

21. Bodner J, Wykypiel H, Wetscher G, Schmid T. First experiences with the da Vinci operating robot in thoracic surgery. Eur J Cardiothorac Surg. 2004;25:844-51.

22. Bodner J, Wykypiel H, Greiner A, Kirchmayr W, Freund M, Margreiter R, et al. Early experience with robot-assisted surgery for mediastinal masses. Ann Thorac Surg. 2004;78:259-66.

23. Bodner J, Zitt M, Ott H, Wetscher G, Wykypiel H, Lucciarini P, et al. Robotic-assisted thoracoscopic surgery (RATS) for benign and malignant esophageal tumors. Ann Thorac Surg. 2005;80: 1202-6.

24. Park BJ, Flores RM, Rusch VW. Robotic assistance for video-assisted thoracic surgical lobectomy: technique and initial results. J Thorac Cardiovasc Surg. 2006;131:54-9.

25. Kutlu AC, Goldstraw P. Tracheobronchial sleeve resection with the use of a continuous anastomosis: results of one hundred consecutive cases. J Thorac Cardiovasc Surg. 1999;117:1112-7.

26. Ishikawa N, Sun YS, Nifong LW, Oda M, Ohta Y, Watanabe G, et al. Thoracoscopic robot-assisted bronchoplasty. Surg Endosc. 2006;20: 1782-3. 